\title{
Grupos y estrategias para la defensa biocultural del territorio en Felipe Carrillo Puerto, Quintana Roo*
}

\section{Groups and strategies for the biocultural defense of the Felipe Carrillo Puerto territory in Quintana Roo, México}

\author{
HERMAX RUBÉN ROMÁN SUÁREZ** / MARÍA AMALIA GRACIA*** \\ HÉCTOR NICOLÁS ROLDÁN RUEDA**** / JUAN MANUEL PAT FERNÁNDEZ*****
}

\begin{abstract}
In this article we analyze different collaborative strategies implemented by women, peasants, producer families and civil society organizations to counteract social exclusion, food insecurity and biodiversity loss in Mayan ejidos of the municipality of Felipe Carrillo Puerto, Quintana Roo. Through Participatory Action Research (PAR), which uses tools and methodologies from social anthropology, we explored the interests and motivations involved in the formation of these associative working groups, while concurrently identifying their limitations, advantages and contributions to the biocultural defense of the territory. The results show the importance of adopting agroecological practices to counteract deeply exclusionary structures that prevail within the ejidos. They also reaffirm the need to co-construct and generate public policies and programs according to the particular socio-economic contexts and needs to generate well-being and social inclusion of historically subalternized groups and towns.
\end{abstract}

Key words: agroecology, collective action, economic solidarity, associative work, self-management, food sovereignty, cultural resistance, Mayan milpa

\section{Resumen}

En este trabajo se analizan diversas estrategias colaborativas implementadas por mujeres, campesinos, familias productoras y organizaciones de la sociedad civil para contrarrestar la exclusión social, la inseguridad alimentaria y la pérdida de biodiversidad en ejidos mayas del municipio de Felipe Carrillo Puerto, Quintana Roo. Mediante una investigación acción participativa (IAP), que retoma herramientas y metodologías de la antropología social, se exploran los intereses y motivaciones involucrados en la conformación de estos grupos de trabajo asociativo, identificando sus limitaciones, beneficios y aportaciones en la defensa biocultural del territorio. Los resultados muestran la importancia de la adopción de prácticas agroecológicas para contrarrestar estructuras profundamente excluyentes que prevalecen en los ejidos y la necesidad de coconstruir políticas y programas acordes a los contextos y necesidades socioeconómicas particulares para garantizar el bienestar y la inclusión social de grupos y pueblos históricamente subalternizados.

Palabras claves: agroecología, acción colectiva, economía solidaria, trabajo asociativo, autogestión, soberanía alimentaria, resistencia cultural, milpa maya

\footnotetext{
* Artículo recibido el 04/02/20 y aceptado el 02/06/20.

** El Colegio de la Frontera Sur (Ecosur). Av. Centenario km 5.5, 77014, Chetumal, Quintana Roo <hrrs1989@gmail. com>. ORCID: 0000-0003-4938-4976

*** Ecosur <magracia@ecosur.mx>. ORCID: 0000-0002-1920-5618

**** Ecosur <nicoroldan19@gmail.com>. ORCID: 0000-0003-3726-5910

*****Ecosur <jpat@ecosur.mx>. ORCID: 0000-0001-6009-5492
} 


\section{Introducción}

$\mathrm{E}$ n México hay centenares de poblaciones en resistencia ante la afectación de sus territorios debido a la supremacía que leyes y políticas públicas otorgan a industrias energéticas, extractivas y megaproyectos de desarrollo (Toledo, 2015; Rosado y VeraHerrera, 2019). En el sureste, el agronegocio y el turismo subordinan las formas de vida comunitarias y ceden el uso y control de las tierras a empresas públicas o corporaciones privadas en detrimento de los intereses y necesidades de las comunidades indígenas y campesinas (Sandoval, 2020; Gutiérrez y Del Pozo, 2019).

Entre sus múltiples problemáticas, las poblaciones mayas peninsulares enfrentan despojos, acaparamientos y reordenamientos territoriales, desplazamientos y migraciones forzadas generadas por el turismo, explotación de sus bienes naturales debido a las demandas del mercado globalizado, subordinación de mujeres, desvalorización y abandono de actividades socioculturales, organizativas, productivas y reproductivas que tienen a la milpa como eje (Uc, 2020).

La poca fertilidad de los suelos, las sequías cada vez más frecuentes y la búsqueda por satisfacer necesidades materiales y no materiales obligan a algunos campesinos y pequeños productores a utilizar agroquímicos y semillas híbridas o transgénicas que, además de empobrecer su dieta, crean dependencia de paquetes tecnológicos que contaminan los suelos y dañan la salud (Álvarez-Buylla y Piñeyro-Nelson, 2013).

Con la pérdida de semillas nativas, prácticas agrícolas, conocimientos, historias y narrativas locales se generan profundas transformaciones en sus formas de vida y cosmovisiones; el tejido social comunitario se desarticula y la relación sagrada con el maíz (Ixi'im), con la Santa Gracia como lo llaman los abuelos, se olvida (Uc, 2019; Chi, 2009).

Frente a estos procesos desestructurantes, florecen las formas organizativas, productivas y reproductivas comunitarias características de las tradiciones indígenas y campesinas. Estas modalidades, basadas en la reciprocidad, la cooperación y la solidaridad, que son parte de la herencia biocultural de los pueblos mayas peninsulares, se resignifican y articulan con diversos actores y movimientos sociales emergentes.

Analizando este tipo de acciones colectivas en territorios de México y América Latina, Gracia (2015a) observa que las demandas de los distintos grupos reclaman, tanto al Estado como al sector privado, derechos sociales, políticos, económicos y culturales. De acuerdo con la autora "estas experiencias cuestionan un modelo de desarrollo monocultural y destructivo, destacando la necesidad de desmercantilizar los bienes comunes a partir de la defensa de la tierra y el territorio como espacios de lucha y reivindicación de la vida" (Gracia, 2015a: 22).

En un sistema capitalista que antepone el individualismo, el consumo desmedido, la acumulación económica y material por encima de la vida y la biodiversidad, epistemologías indígenas, como el Buen vivir (Sumak Kawsay) de los pueblos quechuas y aymaras en Bolivia y Ecuador, resurgen y cuestionan el desarrollo, la modernidad occidental y el eurocentrismo, reivindicando relaciones holísticas y de interdependencia entre los seres humanos con otros seres vivos y con la Madre Tierra (Giraldo, 2014).

En la cosmovisión maya peninsular, el kíimak óolal, que puede traducirse al español como un estado de bienestar, dicha o alegría del alma, remite a un equilibrio espiritual, mental, material y social que se alcanza honrando a los ancestros y a Dios mediante múltiples actividades cotidianas: ofrendas (matán), primicias ${ }^{1}$ (tich'óolal, janlil kool), ceremonias y festividades que fortalecen los vínculos comunitarios, la producción y reproducción simbólica y cultural.

Desde la década de los setenta del siglo pasado, en el municipio de Felipe Carrillo Puerto, se han implementado políticas públicas y programas gubernamentales para establecer zonas de aprovechamiento forestal y agrícola, de protección al patrimonio biocultural y a la población vulnerable, tales como reservas bioculturales, proyectos ecoturísticos o pagos por servicios ambientales (PSA) (García-Frapolli, 2015).

En estos contextos, y apelando a sus formas organizativas, productivas y de reproducción comunitaria, las familias y poblaciones mayas de la zona han buscado articular maneras cooperativas y sustentables de producción, comercialización y consumo de semillas, alimentos y otros insumos para dinamizar economías locales y solidarias, satisfacer necesidades materiales $\mathrm{y}$ no materiales y mejorar sus condiciones de vida (U’yool ché, 2005).

Trabajos como el de la asociación civil U'yool ché (2005) y García-Frapolli (2015) muestran las principales problemáticas, tensiones y limitantes que estos procesos han presentado y presentan: sobresalen las concesiones de cientos de hectáreas a empresas $\mathrm{y}$ actores privados para la ganadería y la siembra de monocultivos, la inequidad en el reparto y tenencia de las tierras, así como la interiorización de una lógica

\footnotetext{
1 Literalmente significa "comida de la milpa". Se ofrendan las primeras cosechas de la milpa a los señores del monte y se
} preparan platillos tradicionales que son repartidos entre familiares y vecinos. 
de mercado y el predominio de una cultura política individualista, asistencialista y clientelar.

Con la intención de aportar y actualizar estas discusiones, en el artículo se identifica y analiza cómo se ponen en juego las modalidades de producción para la reproducción de la vida en ejidos mayas pertenecientes al municipio de Felipe Carrillo Puerto, Quintana Roo. Para ello, mapeamos participativamente a diferentes actores que confluyen en grupos de trabajo asociativo para contrarrestar la exclusión social, la inseguridad alimentaria y la pérdida de biodiversidad en sus territorios.

Al estudiar estas experiencias, puestas en práctica sobre todo por mujeres, campesinos, familias productoras y organizaciones de la sociedad civil, no sólo consideramos los aspectos productivos vinculados a su trabajo, sino que ponderamos los aspectos económicos, político-organizativos, culturales y simbólicos, al entender que son fundamentales para su reivindicación y reconocimiento (Gracia, 2015a).

$\mathrm{El}$ artículo se interroga sobre la forma en que los grupos de trabajo asociativo de producción sustentable y agroecológica contribuyen a satisfacer las necesidades de sus protagonistas, generando circuitos, expresiones y espacios de economías solidarias que puedan cuestionar y redefinir las relaciones de poder, desnaturalizando relaciones de explotación y subordinación imperantes en el capitalismo colonial moderno.

\section{Antecedentes}

Entre los debates teóricos que aluden a las prácticas socioeconómicas emergentes y alternativas en América Latina, encontramos los aportes de Coraggio (2011) y Razeto (2006), quienes, retomando a Polanyi (2007), mencionan que la sostenibilidad de emprendimientos organizativos, productivos y reproductivos solidarios dependerá de las habilidades y disposiciones de sus protagonistas para contribuir a la transformación de estructuras sociales profundamente desiguales y excluyentes.

En estos procesos, que no están exentos de obstáculos y contradicciones, se constituyen los sujetos sociales y políticos a través de sus prácticas cotidianas (Gracia, 2015b). Analizamos las tensiones que enfrentan estos grupos "con instancias heterónomas y campos de poder para darse sus propias formas de regulación y sus discursos, simbologías e imaginarios" (Gracia 2015a: 33), así como los intereses y motivacio- nes que llevan a los protagonistas de estas dinámicas a generar estrategias participativas para mejorar sus condiciones de vida.

Las estrategias llevadas a cabo por estos grupos son resultado de un proceso de diálogo, reconocimiento y participación entre mujeres, hombres, campesinas, campesinos, familias productoras y organizaciones de la sociedad civil, las cuales abarcan una gama de acciones colectivas, prácticas económicas, culturales y socioproductivas sobre bases distintas del protagonismo, la competencia, la dominación patriarcal, la explotación, la mercantilización y la depredación que caracterizan a la economía capitalista (Coraggio, 2011).

La experiencia de La Vía Campesina (LVC), organización campesina internacional,

demuestra el potencial de la agroecología para reivindicar el papel de la agricultura familiar, dinamizar economías solidarias, mercados locales y restablecer nuestra realidad material en el contexto de un sistema alimentario y un mundo rural devastados por el agroextractivismo y la Revolución Verde [Lappé et al., 1998: 25].

LVC propuso el concepto de soberanía alimentaria (sA), definido como el derecho de los pueblos a decidir sus propias políticas agropecuarias y controlar sus sistemas alimentarios, incluyendo la protección de sus semillas, mercados locales, bienes naturales, territorios, culturas alimenticias y modos de producción tradicionales. ${ }^{2}$

Para las poblaciones mayas peninsulares, mantener un relativo grado de soberanía alimentaria ha sido posible gracias al cultivo de milpa, actividad que por milenios se ha perfeccionado para beneficio de estas comunidades y de la humanidad (CEMDA, 2017). La agricultura familiar, que ha permitido la sobrevivencia, reproducción social, simbólica y cultural de estos grupos, se encuentra amenazada por los intereses económicos de un puñado de empresas transnacionales como Bayer-Monsanto, Syngenta, Pioneer, que pretenden controlar el mercado alimenticio a nivel global, apropiándose de las semillas mediante patentes y derechos de obtención, y restringiendo y criminalizando su uso y libre intercambio (Álvarez-Buylla y Piñeyro-Nelson, 2013; Bartra, 2016).

De acuerdo con Giraldo, la diferencia entre la agricultura familiar y el agronegocio radica en el problema del habitar: "Mientras que la primera hace su casa en la tierra, el agronegocio busca explotarla, objetivarla y

2 La Vía Campesina (2002), Soberanía Alimentaria, panfleto distribuido en la Cumbre Mundial de la Alimentación, Roma, Italia. 
economizarla. Mucho más que un terreno homogéneo para acumular capital, la tierra para indígenas y campesinos constituye un espacio habitado que sirve de soporte a su existencia" (Giraldo, 2016: 76).

Pese a los múltiples intentos por desarticular las formas de vida comunitarias para integrarlas al mercado globalizado, las familias y ejidos mayas peninsulares, a través de sus prácticas sociales, culturales, simbólicas, productivas y reproductivas asociadas a la milpa, reivindican su derecho a la libre determinación y contribuyen a la soberanía alimentaria y la defensa biocultural de sus territorios (Uc, 2019).

\section{Región de estudio}

El estado de Quintana Roo se compone de once municipios, seis ubicados en el norte, tres en el centro y dos en el sur (INEGI, 2016). La zona norte se distingue por una fuerte inversión de capital privado, al ser la región turística; en la zona central -la de mayor rezago y marginación- se ubica el grueso de la población indígena, y en la zona sur encontramos grandes extensiones mecanizadas de cultivos comerciales y la capital del estado, la ciudad de Chetumal.

El municipio de Felipe Carrillo Puerto pertenece a la zona central. Está conformado por 87 ejidos (Ejido Felipe Carrillo Puerto, 2005), tres de los cuales se escogieron para realizar trabajo de campo: Betania, Laguna Kaná y Yoactún (véase mapa 1), debido a su tradición comunitaria reflejada en la diversidad de prácticas organizativas, socioeconómicas, culturales, religiosas y políticas asociadas a la milpa maya ( $\mathrm{kool}$ ).

Los cronistas de Felipe Carrillo Puerto, Carlos Chablé y Mario Chan, mencionan que la microrregión que comprende la zona de estudio comenzó a poblarse en los años treinta del siglo pasado por familias provenientes, en su mayoría, de localidades del sur de Yucatán, como Peto, Tikul y Oxcutzcab, después del periodo conocido como Guerra de Castas.

Las primeras personas que llegaron a estos territorios se dedicaban sobre todo a la actividad chiclera, estableciéndose por temporadas en pequeños caseríos y campamentos (Villa Rojas, 1978). En realidad, esta actividad no benefició a los trabajadores, ya que las ganancias se iban mayoritariamente a compañías contratistas (Pérez Aguilar, 2014).

Los abuelos de Laguna Kaná y los cronistas de Felipe Carrillo Puerto cuentan que en esa época hubo sequías, hambruna, plagas de langostas y epidemias de viruela, por lo que se producían movilidades y migraciones constantes. En años recientes, pobladores locales han encontrado en la espesura de la selva vestigios arquitectónicos de antiguos asentamientos, los cuales se cree fueron abandonados por esas razones. En esta microrregión algunas familias siguen man-

Mapa 1. Comunidades de estudio: Betania, Laguna Kaná y Yoactún

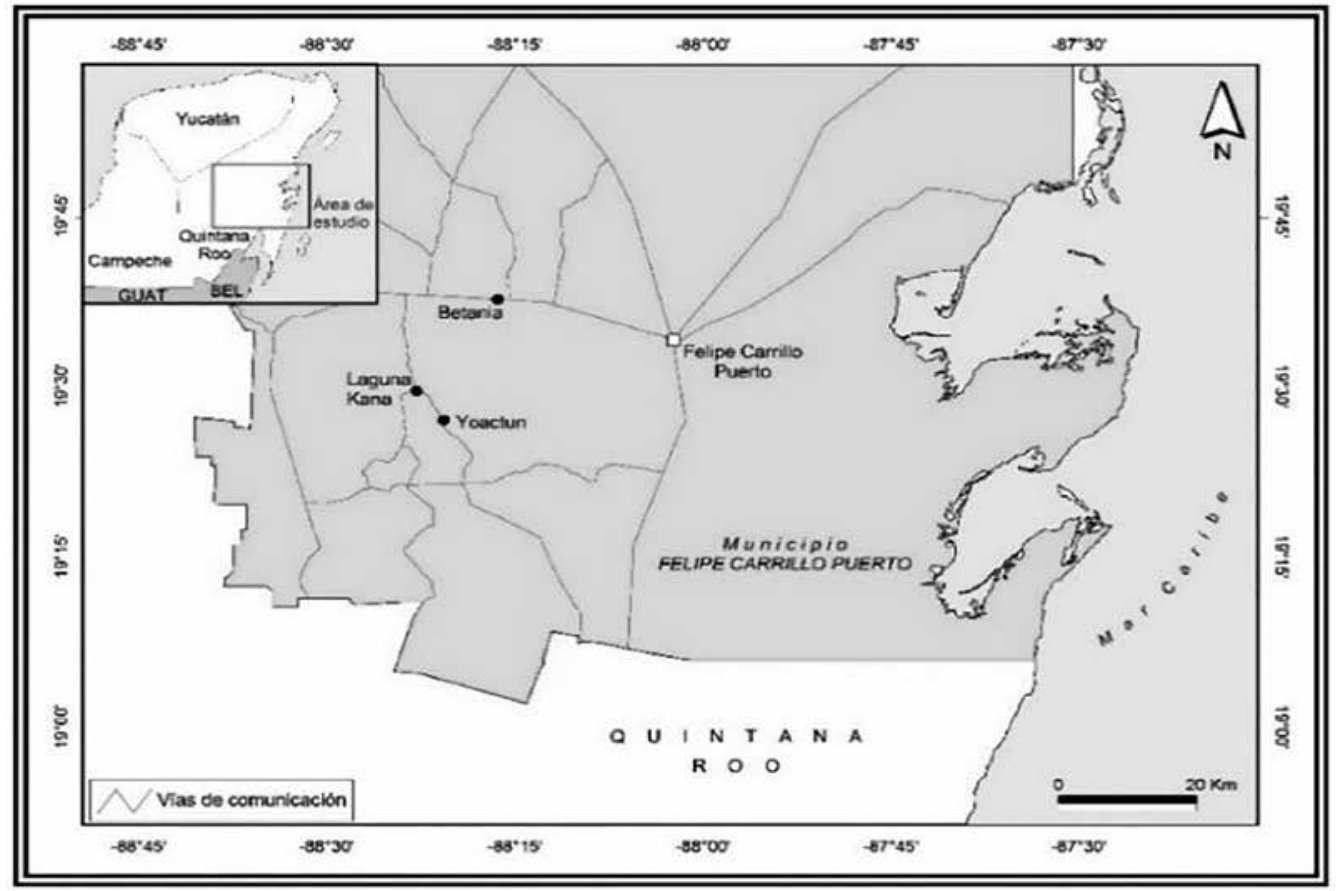

Fuente: Holger Weissenberger, Laboratorio de Análisis de Información Geográfica y Estadística de El Colegio de la Frontera Sur (Ecosur) Unidad Chetumal. 2019. 
teniendo vínculos con los centros ceremoniales ${ }^{3}$ de Chancáh Veracruz y Tixcacal (Aviña, 2001), lo cual demuestra la preservación de sus prácticas tradicionales y lugares sagrados.

Estos ejidos, caracterizados por su aislamiento geográfico, exclusión social y vulnerabilidad ante fenómenos naturales (huracanes, sequías, incendios), experimentan múltiples carencias de infraestructura y precariedad generalizada en servicios de salud, educación, comunicaciones y transporte. Según el Consejo Nacional de Evaluación de la Política de Desarrollo Social (Coneval, 2015), en las comunidades pertenecientes al municipio de Felipe Carrillo Puerto, 71.8 por ciento de la población vive en condiciones de pobreza y 24.7 por ciento en pobreza extrema.

Es en este contexto socioeconómico profundamente excluyente y ambientalmente insostenible, que diversos actores sociales han conformado grupos de trabajo asociativo (GTA), en busca de generar espacios, circuitos y expresiones que reivindiquen el papel protagónico de las familias campesinas en la producción de semillas y alimentos a través del intercambio de saberes de campesino a campesino, la incorporación de prácticas sustentables y agroecológicas y la dinamización de economías locales y solidarias.

\section{Sujetos de estudio: grupos de trabajo asociativo}

La investigación involucró a distintos sujetos y actores sociales (cuadro 1). Dentro de la microrregión de estudio una de las organizaciones con mayor trayectoria es la asociación civil U’yool ché. Esta asociación civil, conformada en la actualidad por un equipo de biólogos, ingenieros agroforestales y especialistas en cooperación internacional para el desarrollo, colabora desde hace 20 años con campesinos y familias productoras en ejidos pertenecientes al municipio de Felipe Carrillo Puerto, promoviendo actividades orientadas a la conservación de los recursos naturales mediante su aprovechamiento sustentable.

Las mujeres y hombres que colaboran con U’yool ché se capacitan como promotores comunitarios, asisten a fiestas de semillas, talleres, asambleas regionales y nacionales en defensa de las semillas nativas y los territorios originarios, intercambios de experiencias y conocimientos con campesinas, campesinos, productores y organizaciones sociales en los estados de Campeche, Chiapas, Quintana Roo y Yucatán.

Los promotores comunitarios intercambian semillas, prácticas y conocimientos asociados a la milpa,

\section{Cuadro 1 Sujetos de estudio}

\begin{tabular}{|c|c|c|}
\hline Actores & Organización / Origen & Estrategias e intereses \\
\hline $\begin{array}{l}\text { Campesinos } \\
\text { y familias } \\
\text { productoras }\end{array}$ & $\begin{array}{l}\text { - Consejo Regional Indígena Popular de Xpujil (CRIPX) } \\
\text { (Campeche) } \\
\text { - Ka Kuxtal Múch Meyaj A. C. (Campeche) } \\
\text { - Desarrollo Económico y Social de los Mexicanos } \\
\text { Indígenas (DEsmi A. C.) (Chiapas) } \\
\text { - U’yool ché A. C. (Quintana Roo) } \\
\text { - Misioneros A. C. (Yucatán) } \\
\text { - La Vía Campesina (Internacional) }\end{array}$ & $\begin{array}{l}\text { Defensa del territorio, preservación y } \\
\text { diversificación de la milpa maya; participación } \\
\text { en fiestas de semillas, transmisión de } \\
\text { saberes campesinos, intercambio de semillas, } \\
\text { incorporación de prácticas agroecológicas }\end{array}$ \\
\hline $\begin{array}{l}\text { Promotores } \\
\text { comunitarios }\end{array}$ & $\begin{array}{l}\text { - Betania, Q. Roo. U’yool ché A. C. } \\
\text { - Peto, Yuc. Misioneros A. C. } \\
\text { - Dzulá, Q. Roo. U’yool ché A. C. } \\
\text { - Yoactún, Q. Roo. U’yool ché A. C. } \\
\text { - Laguna Kaná, Q. Roo. U’yool ché A. C. } \\
\text { - Xpichil, Q. Roo. U’yool ché A. C. } \\
\text { - San Cristóbal de las Casas, DEsmi A. C. }\end{array}$ & $\begin{array}{l}\text { Incorporación de prácticas sustentables y } \\
\text { agroecológicas en huertos, milpas y parcelas; } \\
\text { obstáculos, tensiones, contradicciones, } \\
\text { potencialidades, beneficios }\end{array}$ \\
\hline $\begin{array}{l}\text { Representante } \\
\text { legal, socios y } \\
\text { colaboradores }\end{array}$ & $\begin{array}{l}\text { - U’yool ché A. C., } \\
\text { - Felipe Carrillo Puerto, Quintana Roo }\end{array}$ & $\begin{array}{l}\text { Acompañamiento en la implementación de } \\
\text { prácticas agroecológicas, conformación } \\
\text { de la asociación civil, retos, logros, } \\
\text { potencialidades, alianzas }\end{array}$ \\
\hline $\begin{array}{l}\text { Autoridades } \\
\text { locales } \\
\text { (comisarios y } \\
\text { delegados) }\end{array}$ & $\begin{array}{l}\text { - Betania, Q. Roo } \\
\text { - Laguna Kaná, Q. Roo } \\
\text { - Yoactún, Q. Roo }\end{array}$ & $\begin{array}{l}\text { Organización política en los ejidos, actividades } \\
\text { productivas, población, programas de gobierno }\end{array}$ \\
\hline $\begin{array}{l}\text { Ingenieros } \\
\text { forestales }\end{array}$ & $\begin{array}{l}\text { - Unión Nacional de Organizaciones Regionales } \\
\text { Campesinas Autónomas (UNORCA), } \\
\text { - Felipe Carrillo Puerto, Quintana Roo }\end{array}$ & $\begin{array}{l}\text { Implementación de programas de } \\
\text { ordenamiento territorial y Sembrando Vida }\end{array}$ \\
\hline
\end{tabular}

Fuente: elaboración propia a partir de trabajo de campo, 2019.

3 Los centros ceremoniales son lugares sagrados de los indígenas mayas donde practican su religión, llevan a cabo ceremonias tradicionales y diversas expresiones culturales. 
generan alianzas y estrategias conjuntas en la defensa biocultural de sus territorios, y además asumen el compromiso de reproducir en sus ejidos respectivos los aprendizajes adquiridos para favorecer la divulgación de prácticas sustentables y agroecológicas. En esta investigación analizamos los principales obstáculos, beneficios y potencialidades que estos procesos implican desde el punto de vista de los actores protagonistas en estas dinámicas.

Nos enfocamos sobre todo en las estrategias de los promotores que participan con U'yool ché, aunque también retomamos experiencias y testimonios de campesinas, campesinos y promotores que colaboran con otras asociaciones y organizaciones que conforman la Red Mayense de Guardianas y Guardianes de Semillas (Campeche, Chiapas, Quintana Roo y Yucatán), de la cual U’yool ché forma parte. En el cuadro 1 se muestran los principales sujetos de estudio con los que participamos.

\section{Herramientas de investigación y análisis de datos}

La investigación se basó en técnicas etnográficas y herramientas metodológicas como la investigación acción participativa (IAP), la cual, de acuerdo con Fals Borda (1999), es una filosofía de vida profundamente autorreflexiva que convierte a sus practicantes en per-

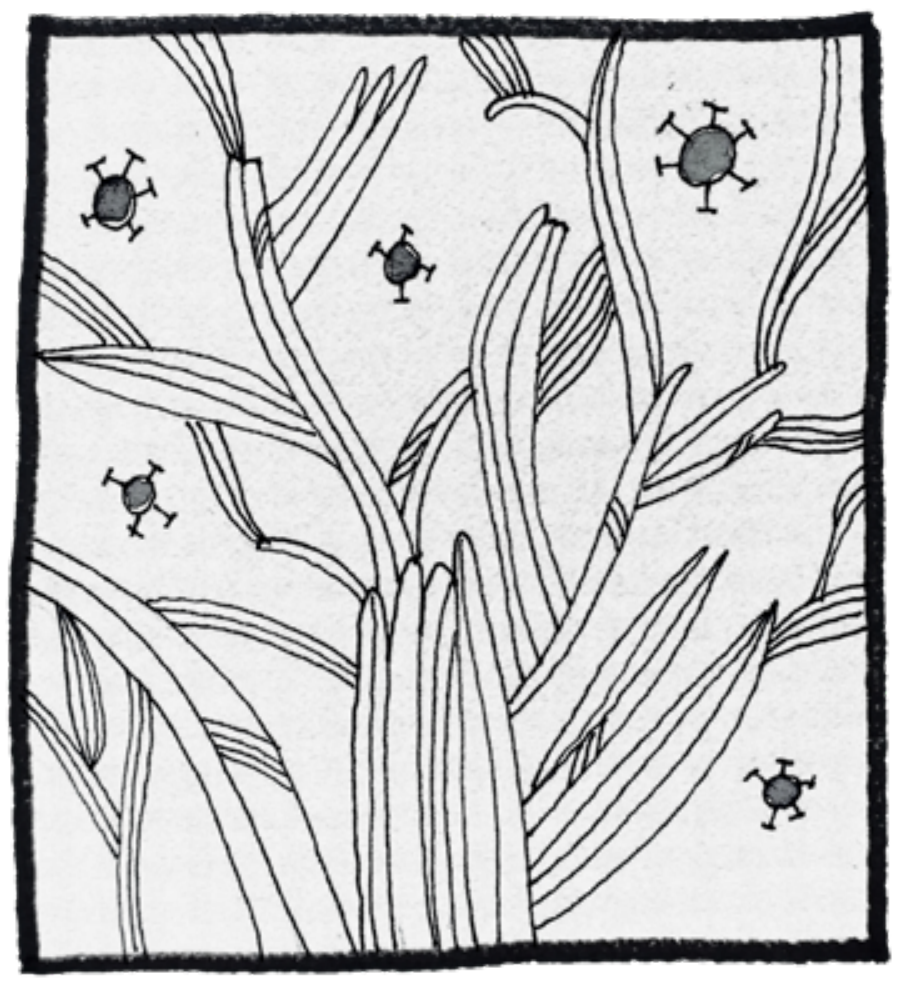

sonas sentipensantes que integran diversos saberes y habilidades para contribuir en la transformación social, de manera corresponsable y sin quitar el protagonismo de actores, organizaciones y grupos en sus procesos histórico-sociales.

En nuestro trabajo de campo realizamos 37 entrevistas: 25 fueron semiestructuradas y se efectuaron en fiestas de semillas (a campesinas, campesinos y productores de Campeche, Chiapas, Quintana Roo y Yucatán, que integran la Red Mayense de Guardianes de semillas); seis fueron entrevistas a profundidad a promotores comunitarios y cuatro a miembros de U'yool ché para conocer los obstáculos, beneficios y potencialidades de la incorporación de prácticas sustentables y agroecológicas en estos territorios; por último, se hicieron dos entrevistas abiertas, una a la representante legal de U'yool ché y la otra a una representante del Programa de Pequeñas Donaciones (PPD) de la Organización de las Naciones Unidas (ONU), que brinda financiamiento a estos grupos a nivel regional.

Las estancias en campo se realizaron de forma aleatoria de marzo a septiembre de 2019 en los ejidos de Betania, Laguna Kaná y Yoactún. El autor principal del artículo participó con promotoras y promotores comunitarios en 25 jornadas de entre cuatro y cinco horas en labores de limpieza (chapeo), siembra y cosecha de huertos, milpas, parcelas y apiarios. También colaboró con U’yool ché en la organización de talleres, fiestas de semillas e intercambios de experiencias en los ejidos de Chunhuás, Dzulá, Señor, Xpichil y en el municipio de Felipe Carrillo Puerto donde la asociación civil tiene su sede.

Como parte de las prácticas rituales vinculadas a la milpa, presenciamos ceremonias de bendición de semillas (loj neek), petición de lluvias (cha'k cha'k) y buenas cosechas para conocer cómo estas expresiones contribuyen al fortalecimiento del tejido social comunitario, la preservación de identidades colectivas y tradiciones culturales.

Nuestra participación en el Primer Congreso de Agroecología en San Cristóbal de las Casas, Chiapas, en encuentros campesinos en la Escuela de Agroecología U Yits Ka'an de Maní, Yucatán y en la Cuarta Asamblea Nacional en Defensa del Maíz en San Juan Bautista, Sahacabchén, Campeche, posibilitó identificar obstáculos y tensiones en procesos de cooperación, conflictos de intereses, diálogos de saberes e intercambios de experiencias entre campesinas, campesinos, familias productoras, asociaciones civiles y organizaciones sociales con instituciones, grupos académicos y centros de investigación.

Finalmente, la información recabada durante la investigación -entrevistas, testimonios, historias de 
vida, grabaciones, diario de campo, tesis, artículos y otras publicaciones- fue examinada con ayuda del software Atlas Ti para triangular datos, realizar análisis comparativos, identificar patrones y categorías emergentes.

\section{Resultados y discusiones}

En este trabajo identificamos y revisamos las estrategias implementadas por GTA conformados por mujeres, campesinas, campesinos, familias productoras y organizaciones de la sociedad civil para contrarrestar la exclusión social, la inseguridad alimentaria y la pérdida de biodiversidad mediante la incorporación de prácticas sustentables y agroecológicas que buscan dinamizar la producción, comercialización y el consumo local y solidario.

Describiremos el contexto socioeconómico y medioambiental en la microrregión de estudio así como las principales actividades productivas y reproductivas. Después analizaremos el impacto de políticas públicas y programas gubernamentales en las prácticas socioproductivas locales y por último mostraremos las estrategias implementadas por los GTA, sus principales obstáculos, beneficios y potencialidades.

\section{Sujetos sociales: actividades productivas, reproductivas y roles de género}

La población de mayor edad en los ejidos de estudio es monolingüe (mayahablantes casi en su totalidad); la mayoría de adultos y jóvenes son bilingües (maya y español) y los niños son sobre todo hablantes de español. En las escuelas no hay profesores bilingües y la lengua materna se utiliza para castellanizar. Según datos de INEGI (2010), en Betania hay 603 pobladores, en Laguna Kaná 951 y en Yoactún 484, aunque es difícil estimar el número preciso debido a la carencia de censos actualizados y a la alta movilidad hacia la zona norte del estado (Cancún y Playa del Carmen, de manera señalada), desplazamiento que se lleva a cabo para trabajar en el sector turístico como camaristas, intendentes, cocineras, meseros y albañiles, entre otros.

Las estrategias productivas y reproductivas incluyen múltiples actividades relacionadas de modo directo con los roles establecidos por el sistema sexo-género. Las mujeres se dedican de manera primordial a labores domésticas: cuidar y alimentar hijos, lavar ropa, cocinar, atender huertos y animales de traspatio, zurcir prendas, urdir hamacas, entre otros quehaceres no reconocidos ni remunerados económicamente. Se casan o tienen hijos siendo muy jóvenes y hay casos en los que padecen violencia doméstica (Enadid, 2014), por lo cual es común encontrar familias monoparentales. La mayoría de los hombres hace milpa para autoconsumo, limpieza de terrenos (chapeo), extracción forestal, apicultura y cacería. Estas actividades se acompañan de ceremonias, rituales, elementos y expresiones simbólicas que favorecen la pervivencia y reproducción identitaria y cultural (U’yool ché, 2005). Otros hombres trabajan como comerciantes, taxistas, palaperos, carpinteros o albañiles en los municipios de Felipe Carrillo Puerto, José María Morelos y Solidaridad.

La población adulta está en riesgo latente debido al nivel de pobreza prevaleciente. Algunos sobreviven con apoyos gubernamentales, por la caridad de familiares y vecinos, bordando blusas (hipiles), urdiendo hamacas o pidiendo limosna en la cabecera municipal. Las abuelas y abuelos poseen el capital humano donde se acumulan conocimientos que se transmiten de generación en generación mediante la tradición oral, la cual se encuentra amenazada por la desvalorización y pérdida de la lengua materna.

La máxima autoridad en estas poblaciones es la asamblea ejidal, conformada sobre todo por reducidos grupos de varones adultos, quienes, amparados por la Ley Agraria, restringen a mujeres, jóvenes y avecindados el derecho a la participación política y a la propiedad de las tierras. Pudimos observar que esta situación jurídica legal es una limitante para fortalecer lazos comunitarios y de cooperación que permitan ampliar las bases de la defensa biocultural de los territorios, pues genera exclusión, desarraigo, conflictos intracomunitarios e intrafamiliares.

Las mujeres continúan teniendo mayores dificultades que los hombres para heredar tierras y ejercer cargos públicos (Vázquez, 2016), lo cual obstaculiza su participación política y su reconocimiento como productoras de semillas y alimentos. De acuerdo con los datos recabados en campo, con delegados y autoridades ejidales, de un total de 186 ejidatarios en Laguna Kaná sólo 12 son mujeres; en Yoactún de 170 únicamente 18 son mujeres y en Betania de 152 sólo 14.

Por otra parte, la mayoría de ejidatarios desconoce la existencia y función de la Procuraduría Agraria, el Tribunal Agrario y el Registro Agrario Nacional (RAN), que se rigen por el derecho occidental, lo que no sólo genera la subordinación legal de sus formas organizativas y productivas, sino que no les proporciona los elementos mínimos para participar en ellas de manera más igualitaria. 
La actividad familiar campesina se encuentra en declive debido a la falta de garantías e incentivos que estimulen la producción, comercialización y el consumo local. Algunos productores que no poseen tierras son contratados temporalmente para trabajar en invernaderos en la siembra de monocultivos en especial de chile habanero (Capsicum chinense) y tomate (Physalis ixocarpa). Al entrevistar a campesinos en el ejido de Betania recabamos testimonios de daños a la salud e intoxicación por exposición prolongada a agroquímicos.

En estos ejidos los campesinos dependen de las lluvias para producir. En la temporada 2019 hubo una sequía crítica, la cual se ha agudizado en años recientes a causa del cambio climático y el calentamiento global, lo que trajo consigo incendios y pérdidas de miles de hectáreas de cultivos (Xantomila, 2019). Los promotores comunitarios con quienes colaboramos mencionan haber perdido hasta 50 por ciento de su producción.

En la foto 1 observamos a don Martín Chuc, un campesino en cuya milpa en el ejido de X-pichil colaboramos. Don Martín, quien sembraba hasta hace poco tiempo de forma convencional (haciendo uso de agroquímicos y semillas híbridas), ha sustituido de modo paulatino estos insumos, debido a que su hijo Luis Ángel Chuc, agroecólogo y colaborador de U’yool ché, consiguió semillas nativas y le enseñó técnicas para elaborar compostas y milpa intercalada con ár-

\section{Foto 1. Desgranando el maíz}

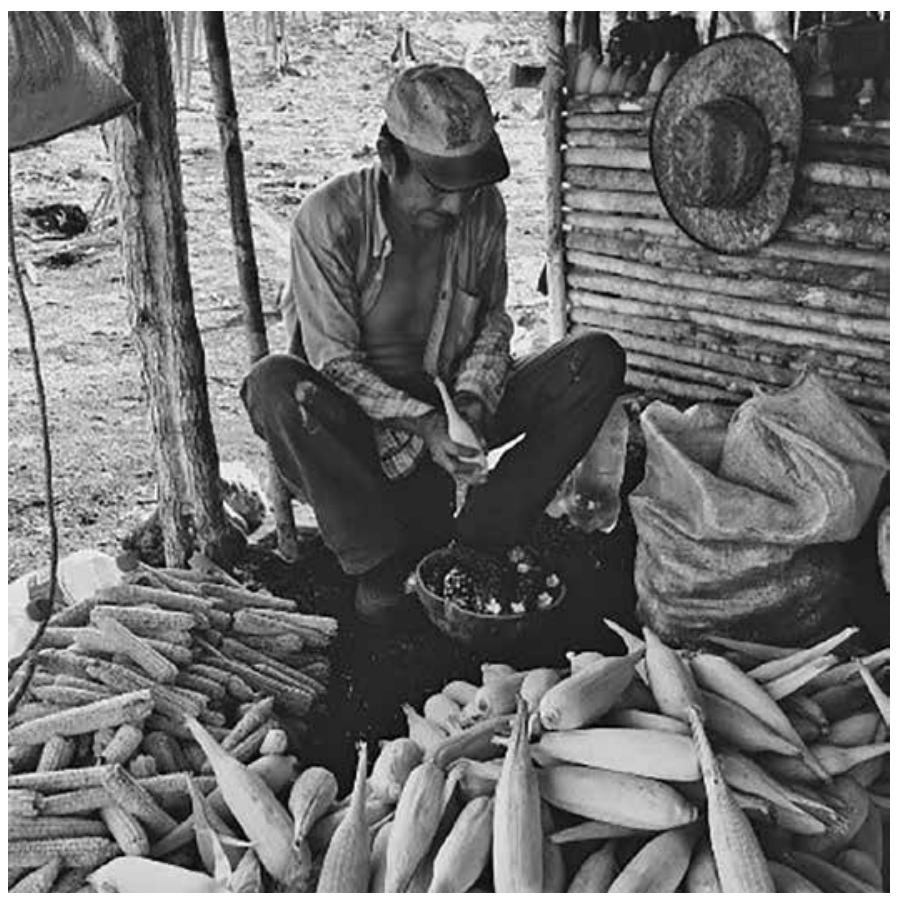

Foto: Hermax Rubén Román Suárez. boles frutales (MIAF), que favorecen la preservación y diversificación in situ de variedades locales de maíz (Pix Cristo, Xmejen Nal rojo y morado) y de tubérculos como el makal (Xanthosoma sagittifolium) y el camote (Ipomoea batatas).

\section{Políticas públicas y efectos en prácticas socioproductivas locales}

Como ya mencionamos, en esta región se han implementado múltiples programas y políticas públicas para impulsar el cuidado y aprovechamiento sustentable de los recursos naturales. Sin embargo, estos programas han sido destinados en esencia a ejidatarios y pocos contemplan y benefician a mujeres, jóvenes, avecindados y otras colectividades (García-Frapolli, 2015). Por mencionar algunos ejemplos, el pago por servicios ambientales (PSA), los reordenamientos territoriales y las declaratorias de reservas bioculturales y ecológicas, como la Reserva de Sian Ka'an, lejos de favorecer a las poblaciones locales las han excluido y criminalizado, generando usufructo, oportunismo, corrupción y enriquecimiento ilícito de funcionarios públicos, cuerpos policiales, autoridades regionales y reducidos grupos de poder en el interior de los ejidos (Gutiérrez y Del Pozo, 2019).

Asimismo, los programas de apoyo a las familias rurales en pobreza extrema, como Solidaridad (19881997), Progresa (1997-2002) y Oportunidades (20022014), en vez de incentivar el desarrollo humano, la producción local de alimentos y la soberanía alimentaria, han interiorizado una cultura política individualista y clientelar, pues, ante la precariedad y carencia generalizadas, las familias se ven forzadas a aceptar beneficios materiales y económicos inmediatos (Rosset y Altieri, 2018).

Pese a ello, al pensar en los cambios en la formulación de políticas públicas y programas gubernamentales debemos tener en consideración que estos apoyos, suficientes o insuficientes, representan para muchas familias la única o primordial fuente de ingresos.

El testimonio de una joven de 28 años originaria de Laguna Kaná da cuenta de la precariedad laboral y económica que viven cientos de madres solteras en estos ejidos. Ante la falta de servicios públicos y recursos económicos operan las redes de apoyo familiares y comunitarias; son frecuentes los casos de niños, abuelos, enfermos o discapacitados que están al cuidado de familiares o vecinos.

Al día me pagan 180 pesos, trabajo para una maestra jubilada en Felipe Carrillo Puerto, trabajo ocho horas 
diarias, allá me dan de comer y a veces me regalan ropa para mis hijos. Hay que hacer gastos siempre para la escuela y la casa; yo quisiera tener para llevar a mis niños a que conozcan la playa o la laguna, ¿tú crees que nos alcanza? Si a veces no puedo ir a Carrillo a trabajar porque no acompleto lo del pasaje, tengo que pedirle fiado a mi hermana o mi vecina que tiene una tienda.

En 2019 comenzó en estos ejidos la puesta en marcha del programa Sembrando Vida, que busca rehabilitar terrenos deforestados o dañados por procesos agrícolas, sembrando alimentos en una primera etapa y arboles maderables después. Sin embargo, los requisitos para acceder al programa implican dejar la rotación dentro de las zonas de cultivo, la cual es elemental para hacer milpa en estos territorios debido al tipo de suelos (Acosta y Vera, 2019). Esto es contrario a las prácticas agrícolas locales, pues los campesinos no siembran en un solo lugar ni en una sola temporada y saben que después de cierto tiempo es necesario dejar descansar las tierras para que se regeneren. En palabras de un campesino originario del ejido de Yoactún:

Entré a Sembrando Vida, mis hermanos no pudieron, que porque aquí (Yoactún) éramos muchos y sólo se podía una persona por familia. Aunque se tardaron más de cinco meses en el papeleo y en regularizar mi situación, ya el mes pasado me dieron lo correspondiente a dos pagos, aunque se quedaron lo de los otros tres meses que por más que los peleé nunca me llegaron. Dijeron que fue recurso a fondo perdido. Yo veo bien el programa, nadie nos había dado tanto, ya me dieron semillas y algunas plántulas, aunque platiqué con un vecino y él fue afectado por la limpia (quema) de terrenos que hicieron alrededor de sus apiarios por lo que su producción bajó casi la mitad, apenas fuimos a ver sus jobones ${ }^{4}$ y si se ve que faltó que llegaran más abejitas.

Hubo campesinos que para entrar a Sembrando Vida hicieron desmontes y quemas de cientos de hectáreas, lo que, además de ser contradictorio con los objetivos del programa, afectó la producción apícola. De acuerdo con testimonios de productores locales, los actores y dependencias municipales encargadas de implementar el proyecto incurrieron en actos de corrupción, compadrazgo y favoritismos. Habrá que esperar más tiempo para conocer las implicaciones y efectos que este programa irá teniendo en la región.
Los apicultores en estos ejidos llegan a producir al año hasta dos toneladas y media de miel. Si bien su producción se logra diferenciar por su calidad en el mercado internacional, la ausencia de certificaciones, apoyos para pequeños y medianos productores, la falta de infraestructura adecuada para su manipulación, así como de canales de comercialización, los lleva a vender su producto a intermediarios (Aroche, 2018).

Otros obstáculos que enfrentan los GTA están relacionados con las múltiples necesidades (educativas, socioeconómicas, alimenticias, afectivas) que la mayoría de las familias no tienen resueltas. La carencia de recursos económicos restringe la participación de los promotores comunitarios: un viaje redondo de los ejidos de estudio a la sede de U’yool ché o a poblaciones aledañas donde se participa con otros promotores ronda entre 80 y 160 pesos, lo cual imposibilita la asistencia constante a capacitaciones, talleres y otras actividades. Además, las vías y medios de comunicación y transporte necesarios para impulsar la movilidad y el desarrollo socioeconómico son insuficientes y limitados.

La cada vez mayor renta y venta de tierras y derechos ejidales a particulares y foráneos (comerciantes, ganaderos, políticos, empresarios), debido al agronegocio y la especulación que el turismo y los megaproyectos de desarrollo generan, ha ocasionado la pérdida de asambleas comunitarias y prácticas colectivas que fortalecen el tejido social como las faenas. ${ }^{5}$

Las experiencias analizadas dejan ver que las condiciones de exclusión social, inseguridad alimentaria y pérdida de biodiversidad que prevalecen en esta microrregión son resultado de relaciones colonialistas, capitalistas, clasistas, racistas y patriarcales reflejadas tanto en programas y políticas públicas como en hábitos y actividades cotidianas en ámbitos públicos y privados, ocasionando subordinación, exacerbación de la pobreza y naturalización de las desigualdades, procesos que los GTA buscan contrarrestar.

\section{Estrategias de los grupos de trabajo asociativo}

Las estrategias puestas en marcha por los GTA con los que colaboramos son resultado de un proceso de diagnóstico, diálogoy planeación colectiva entre los diversos actores que conforman estos grupos para identificar sus debilidades, fortalezas y potencialidades $\mathrm{y}$, de

\footnotetext{
4 Troncos ahuecados de maderas locales donde se crían colonias de Melipona Beecheii.

5 Sinónimo de tequio. Servicio comunitario que se hace en el interior de las comunidades, el cual no es remunerado económicamente, sino a través de la adquisición de estatus y prestigio.
} 
acuerdo con ello, conformar expresiones, circuitos, procesos y espacios de incorporación y difusión de las prácticas sustentables y agroecológicas que mejor se adapten a sus contextos y necesidades. En la figura 1 observamos las principales estrategias impulsadas por los GTA.

Si bien los huertos, parcelas agroforestales y milpas de los promotores comunitarios producen poco, promueven un consumo más consciente y responsable y han generado que algunas familias consuman más alimentos locales. Además, han contribuido a dinamizar expresiones de comercio justo y economías solidarias en fiestas de semillas, mercados y tianguis agroecológicos, ya que favorecen el intercambio de semillas, el reconocimiento, la interacción, la vinculación y el diálogo de saberes de campesino a campesino.

Los promotores comunitarios de Betania, Laguna Kaná y Yoactún han incorporado favorablemente abonos orgánicos (lombricompostas, hojarascas, ceniza y estiércol) y ecotecnias (bombas de mecate, celdas solares, sistemas de captación de agua de lluvia y baños secos). Otros contribuyen al mejoramiento participativo de semillas locales, principalmente de maíz (Nal Tel, Xnuk Nal), y algunos elaboran biofertilizantes para controlar plagas a base de especies como el nim (Azadirachta indica) y la chaya (Cnidoscolus chayamansa).

La introducción de innovación tecnológica como el uso de insumos orgánicos para la obtención de productos agrícolas libres de plaguicidas se refleja en la diversidad de especies y variedades que encontramos en huertos, parcelas, milpas, fiestas de semillas, mercados orgánicos y tianguis agroecológicos. Por sus bajos costos para campesinos y familias productoras, la adopción de estas prácticas posee gran potencialidad para ser adaptadas y reproducidas por otras familias y ejidos.

Aunque falta mucho por hacer en materia de equidad de género, los GTA han visibilizado, reconocido y dinamizado el papel de las mujeres en la selección, diversificación y resguardo de semillas, así como en la elaboración de alimentos, artesanías y otros productos. María Ángela Tum promotora comunitaria en el ejido de Betania narra su experiencia:

Yo no tengo estudios, era aún chiquita cuando me mandaron a trabajar para Playa del Carmen, ahí me trataba mal la patrona, me pagaba muy poco, hice de todo: barrí, cuidé niños, lavé loza, hacía tortillas, cocinaba, aprendí panadería, pero nunca me gustó allá, no podía hablar maya y estaba lejos de mi familia.

Desde que me regresé a Betania cuido a mis hijos y a mi mamá que ya está de edad avanzada. He aprendido a hacer pomadas de árnica, infusiones, jabones, shampoo, hago conservas con frutas de temporada, ahorita tengo dulce de ciruela. Ahí la vamos pasando, el huerto nos da chilito, tomate, yuca. Tengo mis animalitos, pollos, gallinas y conejos. Ahorita tengo aguacate, guanábana, plátano, calabaza y naranja agria.

Mi esposo produce miel para las conservas y dulces que hago. U’yool ché nos dio lombrices californianas, las reproducimos y las usamos para compostear. Mis hijos me ayudan a vender cuando nos sobra cebollín, tomate, rábano o chile, la gente ya sabe que tengo y pasan a comprarme o intercambiamos.

\section{Figura 1. Estrategias para la defensa biocultural de los territorios}

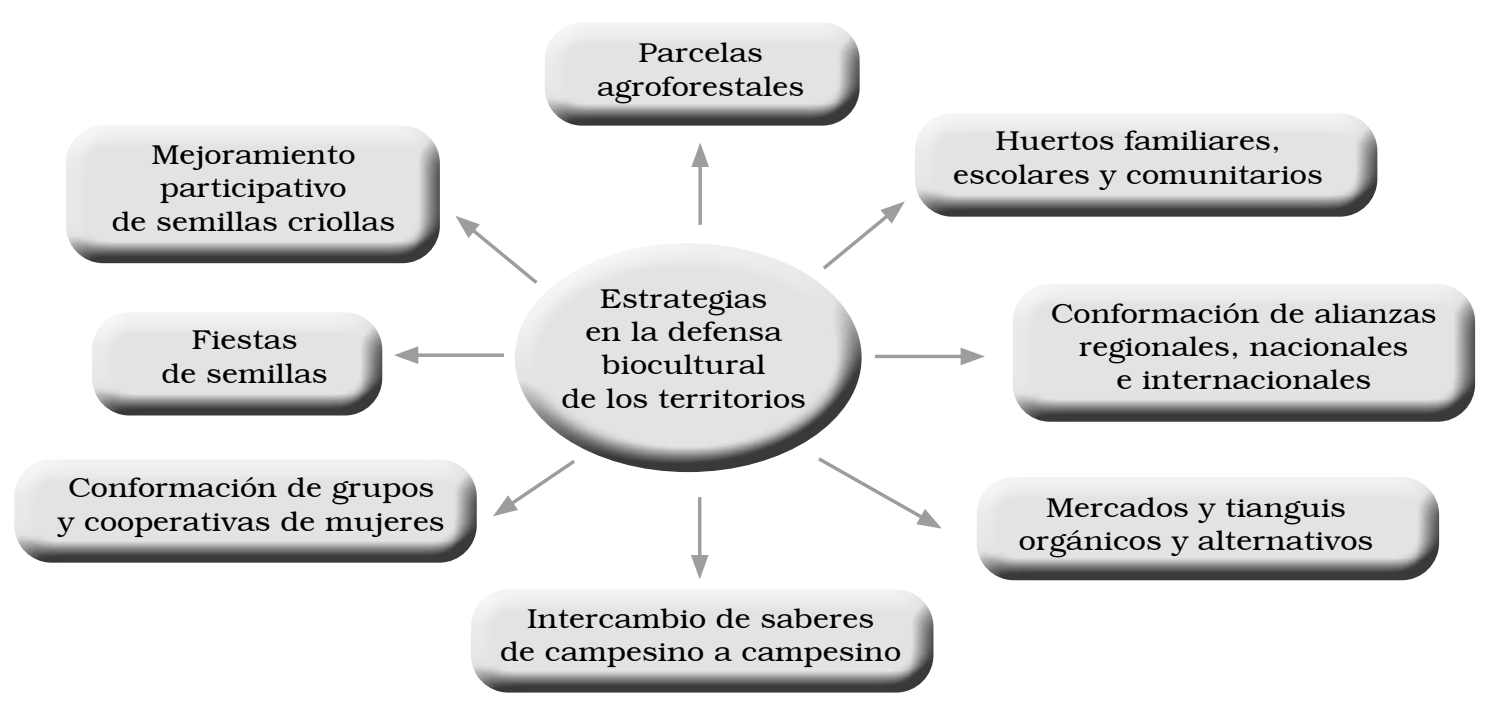

Fuente: elaboración propia a partir de trabajo de campo, 2019. 
Este testimonio demuestra cómo la adopción de prácticas agroecológicas permite generar fuentes de empleo locales e ingresos económicos extras, además de diversificar y optimizar la producción haciendo partícipes a familiares y vecinos.

La participación de los promotores comunitarios ha sido determinante para la organización de fiestas de semillas. Los preparativos de estas actividades buscan involucrar a diversos actores: comités de padres de familia, autoridades locales, grupos artísticos y deportivos locales, artesanos, mujeres, niños y jóvenes. Las familias anfitrionas donan masa, maíz, frijol, sal y aceite en la medida de sus posibilidades; las mujeres preparan la comida que consiste en platillos tradicionales (chilmole, frijol con puerco, pib o relleno negro), muelen maíz, hacen tortillas, prestan trastes, pailas y otros insumos; los jóvenes acondicionan espacios: montan templetes, sillas, mesas, lonas y equipo de sonido. El trabajo cooperativo y solidario realizado en estas celebraciones fortalece los vínculos y la organización comunitaria, las prácticas culturales locales y el sentido de pertenencia.

Cada temporada, don Paulino Cob, promotor en Laguna Kaná, reparte semillas a un grupo de entre cinco y diez campesinos que no tienen, con el compromiso de que, para la siguiente temporada, reproduzcan esta práctica con otros productores, generando una reacción en cadena y contribuyendo así a la preservación y diversificación in situ de variedades locales de maíz resistentes a la sequía como el Nal tel, el Pix Cristo y el Xnuk Nal. En palabras de Paulino:

A mí me vienen a buscar no nomás personas de mi comunidad. Han venido desde otros lados gente que quiere semilla porque las de la Conasupo o las que les da el gobierno no sirven, se pican, yo se las agarro porque soy buena onda pero no la consumo. Intercambio por otras cosas que me puedan dar, además de las semillas les digo cómo deben sembrarlas, en qué momento, hay que fijarse en la luna, en las semillas con las que van a asociar que tampoco sean malas.

Me fijo a quien le doy semilla, quien la va a valorar y le va a dar buen uso y seguimiento, llevo años haciendo esto, lo aprendí con mi papá y mi abuelo en la milpa. Yo he hablado mucho con personas mayores, algunas ya murieron, de ahí aprendí, también de los cursos que he tomado con U'yool ché, nos enseñaron a hacer bioles y compostas, tengo experiencia participando en fiestas de semillas, hace un año [2018] que se hizo en mi comunidad, fui anfitrión.
Hay personas que me tiran de a loco porque siembro en otros tiempos que ellos, yo siembro a mediados de julio o dependiendo como estén las lluvias, no te digo que tengo mucho pero tengo calidad, tengo para mi consumo, para mi familia, no compro en la tienda y nunca he usado químicos ni fertilizantes.

Con sus experiencias, los promotores demuestran la importancia de la preservación de semillas, la transmisión de saberes, el reconocimiento, la confianza, la reciprocidad y las prácticas culturales y simbólicas asociadas a la milpa.

El grupo de promotores de Yoactún obtuvo un premio en la fiesta de semillas de Betania, Quintana Roo (2019) por su labor en el mejoramiento participativo de maíz blanco $\mathrm{X}-\mathrm{Nuk} \mathrm{Nal} .{ }^{6} \mathrm{El}$ reconocimiento se otorgó a la mazorca mejor cultivada, resistente a plagas, sequías y producida sin uso de agroquímicos. Este grupo también recibió el pase de canasta en la fiesta de semillas de Betania, un elemento simbólico que los compromete a ser anfitriones en la próxima fiesta de semillas en Yoactún en 2020.

La preservación de la lengua materna, las semillas y saberes locales, festividades y ceremonias de petición, bendición y agradecimiento son elementos que permiten reproducir, reivindicar y resignificar las formas de vida comunitarias y la cosmovisión de estos pueblos (Morente et al., 2018). Estas expresiones se dan a través de múltiples prácticas y actividades cotidianas. En palabras de don Gerardo Ek, un campesino de Betania de 56 años:

En mi casa jamás se desperdició una tortilla, mi abuelita nos decía que tirar la tortilla al suelo o no comerla toda era pecado. Cuando desgranábamos maíz debíamos agradecer a los señores del monte (Yum K'ax) y recoger todos los granitos que se caían. Nos decía que para hacer el matán (ofrenda) el día del Hanal Pixán (día de muertos) debemos estar alegres si no los difuntos no lo reciben bien, debe hacerse con fe y voluntad.

En sueños se le revelaba a mi abuelita que debía hacer su primicia (ofrenda) y así lo hacía. Había veces que tenía que pedir fiado o sacrificaba alguna gallina de su traspatio, pero no había año que no ofrendara en la iglesia, esto ya se ha ido perdiendo, la mayoría ya no lo hace o sólo cuando es la fiesta grande del pueblo.

Aunque proliferan Iglesias como la pentecostal, la mormona o los testigos de Jehová, las prácticas rituales y ceremoniales en estos ejidos siguen siendo

${ }^{6}$ https: / / www.lapalabradelcaribe.com/u-kimbesaj-ixiim-en-betania/127986/ 
sumamente vastas y tienen como finalidad introducir al hombre en el terreno de lo sagrado. La participación en mayordomías, festividades patronales y ceremonias asociadas a la milpa continúan siendo ejes rectores; incluso la posición social y el prestigio de los pobladores y las familias viene determinado en gran medida por su participación en estas prácticas (Chi, 2009). En la foto 2 observamos una ceremonia de bendición de las semillas llevada a cabo en una fiesta de semillas en San Juan Bautista, Sahcabchén, Campeche.

Estas expresiones tienen una importancia crucial al constituir elementos centrales que dan estructura social y sentido a la comunidad. Además, actúan como barreras frente a la aculturación, pues a través de ellas se acentúan los beneficios de las formas de vida comunitarias, se favorece la pervivencia identitaria, la reproducción y resignificación simbólica y cultural de estos pueblos (Vázquez, 2018).

\section{Conclusiones}

Los GTA han ido generando prácticas y estrategias que aportan distintos elementos a los dinámicos y complejos procesos de defensa biocultural del territorio maya. Mediante espacios y expresiones culturales y agroecológicas, dichas prácticas fortalecen y contribuyen a mejorar las condiciones de vida de las familias y las comunidades rurales.
Los huertos, milpas, parcelas y apiarios que los promotores comunitarios cultivan de forma agroecológica y sustentable, además de funcionar como auténticos refugios bioculturales, son espacios físicos y simbólicos de resistencia y lucha contra la dominación patriarcal, la homogeneización cultural, agrícola y alimentaria, al poseer gran potencial para articular objetivos de sustentabilidad, autonomía, equidad y solidaridad.

El intercambio de semillas y conocimientos de campesino a campesino que se da en fiestas de semillas y tianguis agroecológicos ha permitido rescatar y revalorar especies y variedades que ya no se encontraban en algunas regiones o cuyos usos y propiedades se desconocían. De este modo, se interrelacionan y precisan más las relaciones de los espacios y circuitos productivos para la defensa biocultural del territorio.

Estos espacios contribuyen, asimismo, a visibilizar y politizar a las personas, familias y organizaciones participantes en estas dinámicas, lo que ha favorecido la articulación de redes y grupos conformados a partir del reconocimiento, la vinculación y acción colectiva entre mujeres, hombres, familias, campesinos, comunidades y otros actores.

Compartir experiencias con mujeres y hombres con influencias de la teología de la liberación, la pastoral mayense, el zapatismo y La Vía Campesina ha dado pie a la politización y movilización en defensa de derechos individuales y colectivos por la vía jurídica y legal. De igual forma, el trabajo con colectivos ambientalistas

\section{Foto 2. Ritualidad en fiesta de semillas San Juan Bautista, Sahcabchén, Campeche}

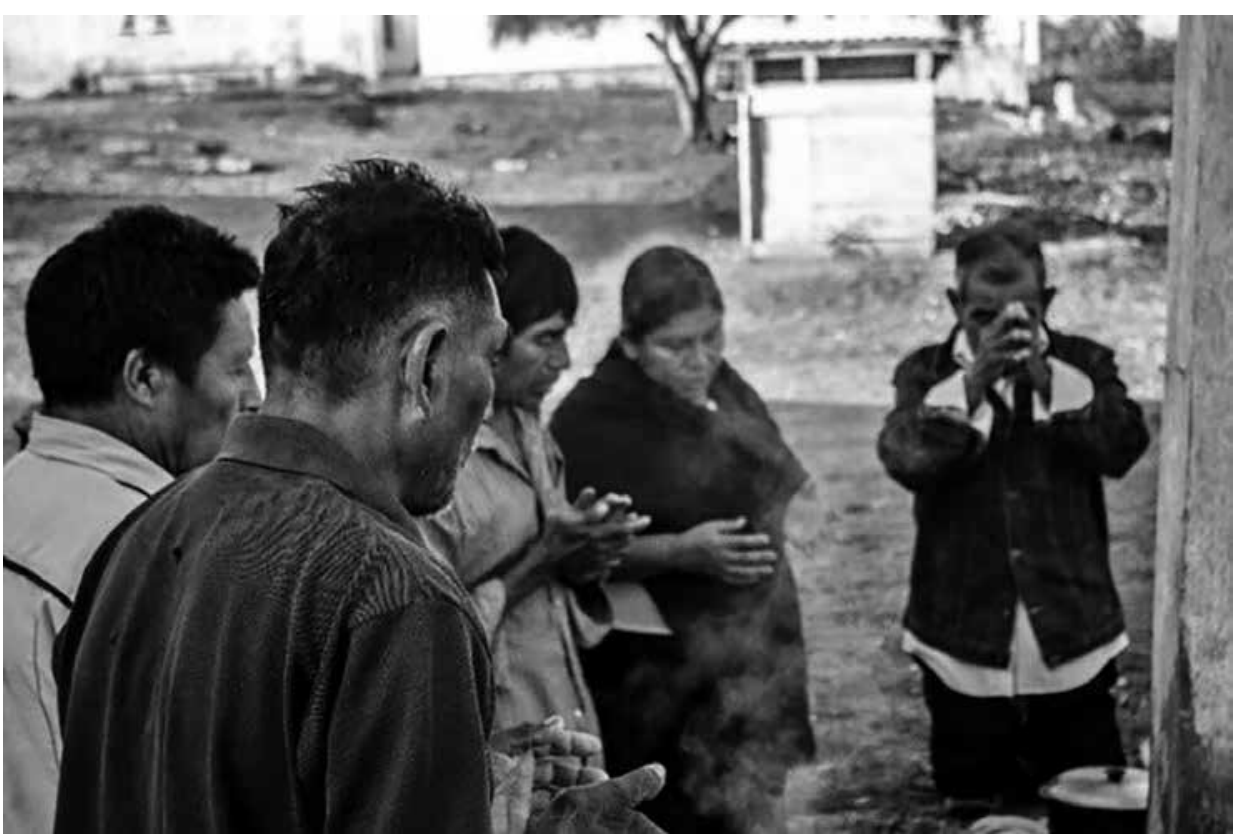

Foto: Hermax Rubén Román Suárez. 
y ecofeministas ha puesto en la mesa el debate sobre la exclusión y la violencia de género que impide el reconocimiento y la participación igualitaria de las mujeres en la vida pública y privada.

Al contrastar nuestros resultados con estudios previos realizados en la región -Roldán y Gracia (2015), Gracia (2015b), García, Rappo y Temple (2016) y García y Gracia (2019)-, observamos que estrategias como mercados orgánicos, tianguis agroecológicos y fiestas de semillas registran un incremento en cuanto al número y la diversidad de actores que participan en estos espacios, lo que refleja la necesidad de articular redes y vínculos para fortalecer los procesos en la defensa biocultural del territorio en la región maya peninsular.

Por lo anterior, consideramos que, desde las organizaciones sociales, indígenas y campesinas, debe continuarse el impulso y la articulación de procesos alternativos de producción, comercialización y consumo de semillas y alimentos que existen en distintos territorios rurales y urbanos del país. En esa línea es necesario sugerir que el Estado debe apoyar las iniciativas sustentables, de economías solidarias y soberanía alimentaria a partir de la organización cooperativa de la economía social del campo como alternativa y estrategia para el desarrollo socioeconómico del medio rural.

\section{Fuentes}

Acosta, Eliana y Ramón Vera

2019 "Sembrando vida va sembrando confusión", en Ojarasca, Suplemento de La Jornada núm. 268, agosto, pp. 6-7.

Álvarez-Buylla, Elena

y Alma Piñeyro-Nelson (coORds.)

2013 El maíz en peligro ante los transgénicos un análisis integral desde el caso de México, Universidad Nacional Autónoma de México, México.

Aroche, Aurora

2018 "El desarrollo de la apicultura sostenible, clave para el desarrollo de los pueblos indígenas de Quintana Roo", en Francico Rosado-May, Mario Chan Collí y Héctor Cálix de Dios (coords.), Sin memoria no hay historia. El rostro humano en la creación de la Universidad Intercultural Maya de Quintana Roo, GLOCAL BEJ, México, pp. 443-455.

Aviña, Gustavo

2001 "Santísima Cruz-Yaaxché: Ejercicio de la territorialidad entre los mayas-maceguales del estado de Quintana Roo", en Patricia Fournier, Saúl Millán y María Eugenia Olavarría. Antropología y simbolismo, Instituto Nacional deAntropología e Historia/Escuela Nacional de Antropología e Historia, México, pp. 105-128.

Bartra, Armando

2016 Las milpas de la ira. "En este mundo cabrón, quien no resiste no existe", Para leer en liber- tad, México <www.redmovimientos.mx/2016/ wp-content/uploads / 2016/10/milpas-de-laira.pdf> [28 de diciembre de 2019].

BORDA, FALS

1999 "Orígenes universales y retos actuales de la IAP”, en Análisis Político, núm. 38, pp. 73-90.

Chi, Hilario

2009 "Así es nuestro pensamiento. Cosmovisión e identidad en los rituales agrícolas de los mayas peninsulares", tesis doctoral, Universidad de Salamanca, Instituto de Iberoamérica.

Cemda

2017 Derechos humanos y patrimonio biocultural, El sistema milpa como cimiento de una política de Estado cultural y ambientalmente sustentable, Centro Mexicano de Derecho Ambiental, México.

Coneval

2015 "Pobreza a nivel municipio 2015, Quintana Roo", en Consejo Nacional de Evaluación de la Política de Desarrollo Social <https: / / www. coneval.org. $\mathrm{mx}$ / coordinacion / entidades / QuintanaRoo/Paginas/pobreza municipal

Coraggio, José 2015.aspx> [ 18 de noviembre de 2019 ].

2011 Economía social y solidaria. El trabajo antes que el capital, Ediciones Abya-Yala/Facultad Latinoamericana de Ciencias Sociales, Quito.

EJido Felipe Carrillo Puerto

2005 "Actualización de Programa de Manejo Forestal Maderable 2006-2010”, Felipe Carrillo Puerto, Quintana Roo, 120 pp.

ENADID

2014 "Encuesta nacional de la dinámica demográfica (ENADID 2014)", en Instituto Nacional de Estadística y Geografía <https://www.inegi. org.mx/programas/enadid/2014/> [4 de junio de 2021].

García, Rocío, Edith RaPPo

Y LUDOVIC TEMPLE

2016 "Innovaciones socioambientales en el sistema agroalimentario de México: los mercados locales alternativos (tianguis)", en Agroalimentaria, vol. 22, núm. 43, pp. 103-117.

García Rocío y María Amalia Gracia

2019 "Nodos, actores y discursos en la generación de alternativas alimentarias locales en Quintana Roo y Yucatán, México, 2000-2016”, en Intersticios Sociales, núm. 17, pp. 175-202 <https://www.redalyc.org/jatsRepo/4217/ $421759176008 / \mathrm{html} /$ index.html $>$ [28 de mayo de 2020].

García-Frapolli, EduARDo

2015 "Exclusión en áreas naturales protegidas: una aproximación desde los programas de manejo", en La naturaleza en contexto. Hacia una ecología política mexicana, Universidad Nacional Autónoma de México (Col. Alternativas), México, pp. 221-236.

Giraldo, OMAR

2014 Utopías en la era de la supervivencia: una interpretación del buen vivir, Itaca/Universidad Autónoma de Chapingo-Departamento de Sociología Rural.

Giraldo, OMAR

2016 "Geopoéticas de la agri-cultura y el agroextractivismo industrial: la pregunta por el habitar", Geograficidade, vol. 5, núm. especial, primavera, pp. $76-88$. 
Gracia, María Amalia

2015a "Indagar el campo de posibilidades de las experiencias de trabajo asociativo autogestionado", en María Amalia Gracia (coord.), Trabajo, reciprocidad y re-producción de la vida, experiencias colectivas de autogestión y economía solidaria en América Latina, El Colegio de la Frontera Sur/Consejo Nacional de Ciencia y Tecnología, México, pp. 17-55.

Gracia, María Amalia

2015b "Movilización de saberes para la construcción de autonomía en comunidades mayas del municipio de Bacalar, Q. Roo, México", en Otra Economía, vol. 9, núm. 17, pp. 136-150. DOI: $10.4013 /$ otra.2015.917.03 [12 de abril de 2019].

GutiÉrRez, RoDrigo

Y EDMUNDO DEL POZO

2019 De la consulta a la libre determinación de los pueblos, Universidad Nacional Autónoma de México/Fundación para el Debido Proceso/ Fundar, Centro de Análisis e Investigación, México.

INEGI

2010 "Catálogo de claves de entidades federativas, municipios y localidades", en Instituto Nacional de Estadística y Geografía <https: / /www. inegi.org. $\mathrm{mx} / \mathrm{app} /$ areasgeograficas $/$ ?ag $=23>$ [ 14 de abril de 2019].

INEGI

"Cuéntame, información por entidad", en Instituto Nacional de Estadística y Geografía <http: / / cuentame.inegi.org.mx/monografias / informacion / qroo/territorio/div_municipal. aspx?tema $=$ me\&e $=23>[24$ de noviembre de 2019].

Lappé, Frances, Joseph Collins,

Peter Rosset y Luis Esparza

2005 Doce mitos sobre el hambre: un enfoque esperanzado para la agricultura y la alimentación del siglo XXI, Icaria Editorial, Barcelona.

Morente, Rubén, Gregorio Vázguez

Joaguín Quiroz, Citlalli Cantú

y Manuel Buenrostro

2018 La religiosidad popular maya, Instituto de la Cultura y las Artes de Quintana Roo, México.

Pérez Aguilar, Raúl Arístides

2014 "El chicle en Quintana Roo: sus caminos y voces", en Cuicuilco, vol. 21, núm. 60, pp. 195-222.

POLANYI, KARL

2007 La gran transformación: crítica del liberalismo económico, Fondo de Cultura Económica, México.

Razeto, Luis

2006 Lecciones de economía solidaria. Realidad, teoría y proyecto, Uvirtual.net, Chile.

ROLDÁN, HÉCTOR

y María Amalia Gracia

2015 "Espacios de intercambio local de productos orgánicos en México. Panorama, tenciones y procesos de aprendizaje", en María Amalia Gracia, Trabajo, reciprocidad y re-producción
ROSADO, SAMUEL

de la vida. Experiencias colectivas de autogestión y economía solidaria en América Latina, Miño y Dávila, Buenos Aires, pp. 285-314.

Y RAMÓN VERA-HERRERA

2019 “ ¿Tren Maya? Auge de proyectos acaparadores, desprecio por la gente", en Ojarasca, Suplemento de La Jornada, núm. 264, abril, pp. 8-9.

Rosset, Peter y Miguel Altieri

2018 Agroecología, ciencia y política, Sociedad Científica Latinoamericana de Agroecología, Riobamba.

SANDOVal, Daniel

2020 Tren maya, sembrando vida y corredor transístmico, impactos en el valor de uso territorial de las comunidades indígenas y campesinas, Pan para el mundo/Centro de Estudios para el Cambio en el Campo Mexicano, México, $41 \mathrm{pp}$.

Toledo, Víctor M.

2015 Ecocidio en México: la batalla final es por la vida, Grijalbo, México.

UC, HeBER

2019 El derecho al territorio, frente a la soya transgénica en Bacalar, Quintana Roo, Pan para el Mundo/Centro de Estudios para el Cambio en el Campo Mexicano, México, 21 pp.

UC, PEDRO

2020 "Múuch’Xíinbal, la organización como asamblea del territorio", en Ojarasca, Suplemento de La Jornada, núm. 276, abril.

U'YOOL CHÉ

2005 "Estudio de Ordenamiento Territorial del Municipio de Felipe Carrillo Puerto", 15 de diciembre.

VÁzgUez, VERÓNICA

2016 "Género y derechos agrarios en México. Reflexiones a más de dos décadas de la Reforma de 1992", en Margarita Velázquez, Verónica Vázquez, Ana De Luca y Dulce María Sosa (coords.), Transformaciones ambientales $e$ igualdad de género en América Latina, Centro Regional de Investigaciones Multidisciplinarias, Cuernavaca, 173-196.

VÁzguez, Gregorio

2018 "El aliento protector de la cultura maya", en Rubén Morente, Gregorio Vázquez, Joaquín Quiroz, Citlalli Cantú y Manuel Buenrostro, La religiosidad popular maya, Instituto de la Cultura y las Artes de Quintana Roo, México. pp. 71-111.

Villa Rojas, Alfonso

1978 Los elegidos de Dios, etnografía de los mayas de Quintana Roo, Instituto Nacional Indigenista, México.

Xantomila, Jessica

2019 "Sequía del 2019 devastó más de 60\% del país: SADER", en La Jornada, 29 de diciembre <https: / /www.jornada.com.mx/ultimas / politica/2019/12/16/sequia-del-2019devasto-mas-de-60-del-pais-sader-3253. html> [20 de diciembre de 2019]. 